\title{
Mechanism of Uranium Reduction and Immobilization in Desulfovibrio vulgaris Biofilms
}

\author{
Malgorzata Stylo, ${ }^{\dagger}$ Nadja Neubert, ${ }^{\ddagger}$ Yvonne Roebbert, $^{\ddagger}$ Stefan Weyer, ${ }^{\ddagger}$ and Rizlan Bernier-Latmani ${ }^{*}{ }^{\dagger}$ \\ ${ }^{\dagger}$ Environmental Microbiology Laboratory, École Polytechnique Fédérale de Lausanne, CH-1015 Lausanne, Switzerland \\ ${ }^{\ddagger}$ Institut für Mineralogie, Leibniz Universitat Hannover, D-30167 Hannover, Germany
}

Supporting Information

ABSTRACT: The prevalent formation of noncrystalline U(IV) species in the subsurface and their enhanced susceptibility to reoxidation and remobilization, as compared to crystalline uraninite, raise concerns about the long-term sustainability of the bioremediation of U-contaminated sites. The main goal of this study was to resolve the remaining uncertainty concerning the formation mechanism of noncrystalline $\mathrm{U}(\mathrm{IV})$ in the environment. Controlled laboratory biofilm systems (biotic, abiotic, and mixed biotic-abiotic) were probed using a combination of $U$ isotope fractionation and X-ray absorption spectroscopy (XAS). Regardless of the mechanism of $U$ reduction, the presence of a biofilm resulted in the formation of noncrystalline U(IV). Our results also show that biotic $U$ reduction is the most effective way to immobilize and reduce $\mathrm{U}$. However, the mixed biotic-abiotic system resembled more closely an abiotic system:

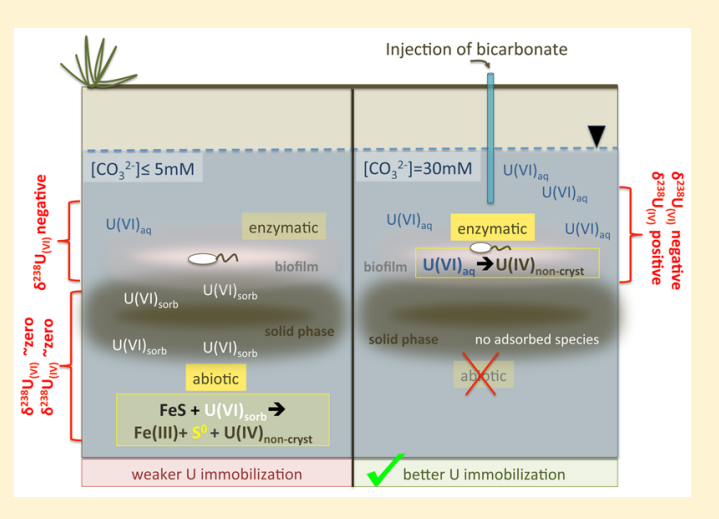
(i) the U(IV) solid phase lacked a typically biotic isotope signature and (ii) elemental sulfur was detected, which indicates the oxidation of sulfide coupled to $\mathrm{U}(\mathrm{VI})$ reduction. The predominance of abiotic $\mathrm{U}$ reduction in our systems is due to the lack of available aqueous $\mathrm{U}(\mathrm{VI})$ species for direct enzymatic reduction. In contrast, in cases where bicarbonate is present at a higher concentration, aqueous $\mathrm{U}(\mathrm{VI})$ species dominate, allowing biotic $\mathrm{U}$ reduction to outcompete the abiotic processes.

\section{INTRODUCTION}

Uranium mining, milling, and chemical treatment left a legacy of uranium contamination around the world. In order to mitigate the negative effect of this contaminant on the environment, human health, and the economy, a combined effort from the research community, engineers, and practitioners is necessary. Bioremediation is a promising strategy that leads to the immobilization of uranium in situ by microbial reduction of labile $\mathrm{U}(\mathrm{VI})$ to less mobile $\mathrm{U}(\mathrm{IV}),{ }^{1-8}$ by biosorption $^{9,10}$ or by bioaccumulation. ${ }^{11,12}$ These methods have the potential to prevent the spread of the contaminant plume and, thus, may improve groundwater quality downstream from the applied engineered solution. An efficient cleanup strategy for U-contaminated sites must be based on a sound understanding of biogeochemical conditions present at the site and on uranium properties. Consequently, knowledge acquired through experimental work should be translated into field recommendations to ensure a successful remediation outcome.

In uranium bioremediation research, most laboratory studies are conducted in the presence of planktonic microorganisms. $^{13-15}$ However, this approach fails to acknowledge the importance of biofilms, which is the most common growth form of microorganisms in the environment. ${ }^{16-18}$ The main structural components of bacterial biofilms are extracellular polymeric substances (EPS), composed of heterogeneous materials that include proteins, lipids, and polysaccharides. ${ }^{19,20}$ EPS contain numerous functional groups, such as carboxyl, phosphoryl, amine, and hydroxyl, and thus potentially can act as a binding or nucleation site for heavy metals. ${ }^{21,22}$ In addition, it was proposed that outer-membrane cytochromes (e.g., MtrC and OmcA in Shewanella oneidensis MR-1), that mediate enzymatic $U$ reduction, are also localized in the EPS. ${ }^{23}$

A recent study carried out with the metal-reducing bacterium Shewanella oneidensis MR-1 showed that the presence of bacterial EPS is correlated with the formation of noncrystalline $\mathrm{U}(\mathrm{IV})$ as a result of $\mathrm{U}(\mathrm{VI})$ bioreduction. ${ }^{15}$ In contrast to crystalline uraninite $\left(\mathrm{UO}_{2}\right)$, which is relatively resistant to oxidation, noncrystalline $\mathrm{U}(\mathrm{IV})$ is more labile and susceptible to reoxidation. ${ }^{24}$ Therefore, it is a less desirable U(IV) bioproduct as it does not guarantee adequate immobilization of the contaminant. Nevertheless, a field study at Rifle, Colorado (USA) demonstrated that noncrystalline U(IV) is a predominant species found in the subsurface after bioremediation. $^{25,26}$ In light of this information, it is critical that research focused on understanding the mechanism governing the

Received: April 8, 2015

Revised: July 13, 2015

Accepted: August 7, 2015

Published: August 7, 2015 
formation of noncrystalline U(IV) in the subsurface include biofilms in addition to planktonic bacteria.

Bargar et al. $^{26}$ proposed that noncrystalline U(IV) was formed as a result of abiotic $U$ reduction, mediated by biologically formed mackinawite (FeS), and subsequent complexation of the produced U(IV) ions by biofilm components, possibly bacterial EPS. Uranium isotope measurements at the same U-contaminated site at Rifle showed a progressive fractionation of the isotopes of aqueous $\mathrm{U}(\mathrm{VI})$ in the groundwater toward lower ${ }^{238} U /{ }^{235} U$, which implies the preferential incorporation of the heavy $U$ isotope into the formed U(IV) solid. ${ }^{27}$ The most recent $U$ isotope findings ${ }^{28}$ demonstrate that, in contrast to abiotic reduction, only enzymatic $U$ reduction results in the accumulation of ${ }^{238} U$ in the formed U(IV) solid. The latter findings necessitate a reevaluation of the mechanism of in situ $\mathrm{U}(\mathrm{VI})$ reduction proposed by Bargar et al. ${ }^{26}$ The extent of isotopic shift reported under field conditions is smaller than that obtained during biotic $U$ reduction in the laboratory, suggesting that a combination of biotic and abiotic processes may be involved in $\mathrm{U}$ reductive transformation in the subsurface.

The remaining uncertainty about the mechanism of noncrystalline $\mathrm{U}(\mathrm{IV})$ formation in the environment is at the root of the present study. The objectives of this work are to deconvolute the mechanism(s) of $\mathrm{U}(\mathrm{VI})$ reduction under various conditions and to identify key processes responsible for the prevalent formation of noncrystalline U(IV) species in the subsurface. These goals are reached through the implementation of biofilm-based experiments and the use of $U$ isotope signatures as a tool capable of distinguishing biotic from abiotic $\mathrm{U}$ reduction.

\section{MATERIALS AND METHODS}

2.1. Biofilm Growing Conditions. To setup actively growing biofilms, a pregrown culture of Desulfovibrio vulgaris was added to sterile and anoxic MOYSL medium ${ }^{29}$ and left to grow for $24 \mathrm{~h}$. At that time, 5 or $30 \mathrm{mM}$ bicarbonate and 400 $\mu \mathrm{M}$ of depleted uranyl acetate, or $400 \mu \mathrm{M}$ of natural $\mathrm{U}(\mathrm{VI})$ in $0.1 \mathrm{M}$ hydrochloric acid, were added. For the inactivated biofilm cases, a pregrown culture of $D$. vulgaris was added to sterile and anoxic MOYSL medium and allowed to grow for 4 days. Subsequently, $0.3 \%$ of sodium azide was added to the cultures in order to inhibit further microbial activity and growth (Figure S1 and Table S1). After $3 \mathrm{~h}$ of incubation with the metabolic inhibitor, $5 \mathrm{mM}$ of bicarbonate and $400 \mu \mathrm{M}$ of depleted uranium(VI) acetate, or $400 \mu \mathrm{M}$ of natural $\mathrm{U}(\mathrm{VI})$ in $0.1 \mathrm{M}$ hydrochloric acid, were added. In all cases, the static biofilms were allowed to grow for 16-17 days.

2.2. Experimental Design. In order to determine the mechanism of $U$ reduction under field relevant conditions, six experiments were set up (Table S2) that varied with respect to the $\mathrm{U}(\mathrm{VI})$ reducing agents. Three main categories, biotic, abiotic, and mixed biotic and abiotic, were set up either as an "Fe" containing system (addition of ferrihydrite ( $\mathrm{Fh}$ )-coated glass slides) or as a "no-Fe" containing system (absence of Fh). In the most complex system (mixed $+\mathrm{Fe}$ ), containing actively growing biofilm, $5 \mathrm{mM}$ of bicarbonate, $400 \mu \mathrm{M}$ of $\mathrm{U}, 10 \mathrm{mM}$ of sulfate, and $\mathrm{Fh}$ minerals (at an average concentration of 2.5 $\mathrm{mM}$ ), a mixture of reducing agents was expected: Bacteria produced dissolved sulfide and Fe(II) sulfide minerals (such as mackinawite) as a result of microbial metabolism, both of which could serve as reducing agents in addition to bacteria. In the mixed-no-Fe system, containing actively growing biofilm, $5 \mathrm{mM}$ of bicarbonate, $400 \mu \mathrm{M}$ of $\mathrm{U}, 10 \mathrm{mM}$ of sulfate, bacteria, and the produced dissolved sulfide species were expected to act as reducing agents. Addition of $30 \mathrm{mM}$ of bicarbonate to the biotic systems allowed for the purely biotic reduction of U(VI) in biofilm systems due to the formation of $\mathrm{U}(\mathrm{VI})$-carbonate aqueous complexes ${ }^{15}$ that precluded the sorption of U(VI) onto the mineral phase and by this ruled out the contribution of abiotic $U$ reducing agents in both biotic setups. In the abiotic systems, inactivation of biomass was performed by addition of the metabolic inhibitor sodium azide (see the Supporting Information for details) and thus left only dissolved sulfide and ferrous iron sulfide minerals as the $\mathrm{U}(\mathrm{VI})$ reducing agents in the abiotic $+\mathrm{Fe}$ scenario and exclusively dissolved sulfide in the abiotic-no-Fe scenario.

2.3. Subsampling and Analytical Methods. Aliquots $(1.5 \mathrm{~mL})$ were withdrawn at time intervals and filtered through $0.22 \mu \mathrm{m}$ membranes in order to quantify the remaining concentration of uranium(VI), sulfate, lactate, and acetate and the buildup of sulfide. Subsamples for sulfide and sulfate were additionally mixed with a $10 \%$ zinc acetate solution (at a 1:5 sample/zinc acetate ratio) in order to capture sulfide. All samples were withdrawn and processed under strict anoxic and sterile conditions. At the last time point (16 or 17 days), a second type of sample was collected for each experimental condition in order to quantify $\mathrm{U}(\mathrm{VI})$ adsorbed on the mineral phase. These subsamples (unfiltered) were incubated overnight with $\mathrm{NaHCO}_{3}$ (at a final concentration of $100 \mathrm{mM}$ ) to preferentially desorb $\mathrm{U}(\mathrm{VI})$ by forming uranyl-carbonate complexes released into solution. Subsequently, the mixture was filtered through $0.22 \mu \mathrm{m}$ membranes.

Uranium remaining in solution or desorbed was analyzed by inductively coupled plasma optical emission spectrometry (ICP-OES) or inductively coupled plasma mass spectrometry (ICP-MS). The sulfide concentration was quantified using the colorimetric Cline method described previously. ${ }^{30}$ Sulfate, lactate, and acetate were measured by ion chromatography (IC).

2.4. Solid Phase Separation. At a time point of 16 or 17 days, the static biofilm was destructively sampled by detachment and homogenization of all the biofilm parts (from the suspension and from the glass slide). Subsequently, the resuspended solid phase (biomass associated with minerals) was separated from the solution by centrifugation for $15 \mathrm{~min}$ at $8000 \mathrm{rpm}$ under anoxic conditions. The solid phase collected for each biofilm experiment was preserved frozen in double anoxic containment (anoxic tubes inside an anoxic Mylar bag) until further analysis.

2.5. X-ray Absorption Spectroscopy (XAS) Analysis. Solid samples were shipped in triple anoxic containment (anoxic tubes, Mylar bag, and anoxic steel canister) to the Stanford Accelerator Laboratory (SLAC). X-ray absorption spectra for uranium and iron were collected at beamline 4-1 of the Stanford Synchrotron Radiation Lightsource (SSRL) while XAS date for sulfur was collected at beamline 4-3. All manipulations were conducted under strict anoxic conditions. More detail on the XAS analysis is available in the Supporting Information.

2.6. Isotopic Measurements. Sample and standards preparation and purification is described in detail in the Supporting Information. The ${ }^{238} \mathrm{U} /{ }^{235} \mathrm{U}$ isotopic composition was measured with a Thermo Neptune Multicollector inductively coupled plasma source mass spectrometer (MCICP-MS), equipped with a "jet interface". For sample 


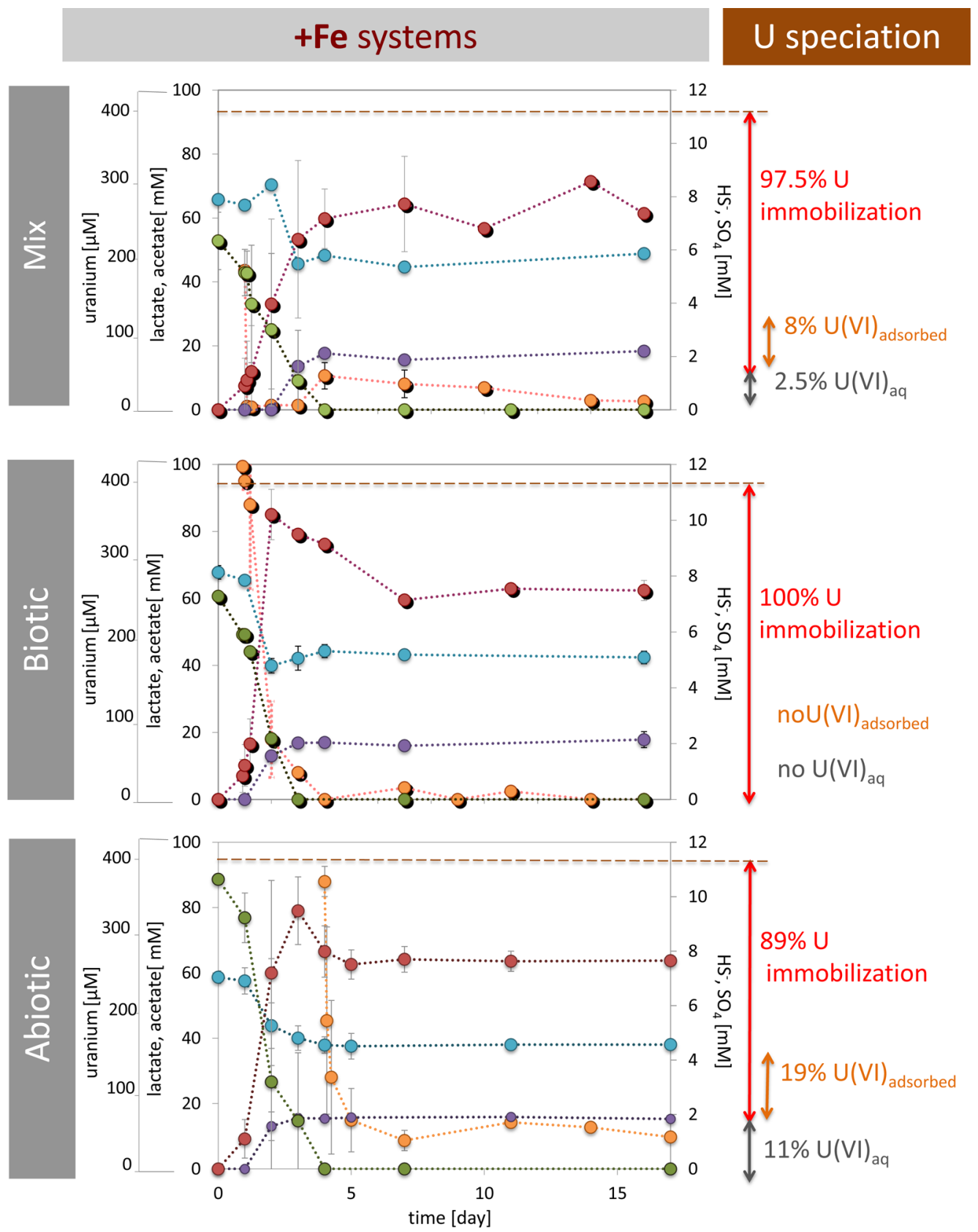

Left $y$-axis

Right y-axis

lactate $\bigcirc$ acetate $\bigcirc$ uranium $\bigcirc \mathrm{HS}^{-} \bigcirc \mathrm{SO}_{4}$

Figure 1. Variation in the concentration of dissolved species (lactate in blue, acetate in purple, uranium in orange, sulfide in red and sulfate in green) over time in biofilm experiments with iron present $(+\mathrm{Fe})$ (in electron acceptor limited conditions). The left $y$-axis corresponds to lactate, acetate $[\mathrm{mM}]$, and uranium $[\mu \mathrm{M}]$ concentrations, and the right $y$-axis represents sulfate and sulfide $[\mathrm{mM}]$ concentrations in the system. $\mathrm{U}(\mathrm{VI})$ was amended after 1 day in the mixed and biotic systems and after 4 days in the abiotic systems (see text for explanation). Horizontal orange dashed lines mark the total concentration of $\mathrm{U}$ added $(400 \mu \mathrm{M})$. On the right side, a qualitative and quantitative visualization of $\mathrm{U}$ species is provided, corresponding to the end of the experiment (16 or 17 days). Fraction of $\mathrm{U}(\mathrm{VI})$ adsorbed is reported relative to amount of $\mathrm{U}$ immobilized. In the mixed system, $\mathrm{U}(\mathrm{VI})$ is removed instantaneously due to rapid sorption.

introduction, an ESI Apex nebulizer (without membrane) was coupled to the desolvation unit of a Cetac Aridus. With this set up, an ion beam of about $4 \times 10^{-10} \mathrm{~A}$ for ${ }^{238} \mathrm{U}$ was routinely achieved for a solution of $50 \mathrm{ng} / \mathrm{g}$ U. Mass bias correction was applied, using the IRMM 3636A double spike and the exponential law. Furthermore, a standard sample bracketing method was applied; i.e., two sample measurements were bracketed by two standard measurements. The results for all sample analyses are reported in the delta notation relative to the IRMM-184 standard (which was also used to conduct the experiments):

$$
\delta^{238} \mathrm{U}=\left[\frac{\left({ }^{238} \mathrm{U} /{ }^{235} \mathrm{U}\right)_{\text {sample }}}{\left({ }^{238} \mathrm{U} /{ }^{235} \mathrm{U}\right)_{\mathrm{IRMM}-184}}-1\right] \times 1000
$$


Each sample was analyzed three times, and the precision is reported as two standard deviations (2 S.D.) of the replicate analyses for each sample (typically $\leq 0.1 \%$ ). Analytical quality, i.e., the accuracy of the measuring protocol, has been regularly tested by analyses of the U standards IRMM-184 and REIMEP 18-A relative to CRM-112A. The results for both standards agreed within those previously reported in the literature. ${ }^{31,32}$ The abundance sensitivity of the MC-ICP-MS was checked before each analysis session using a ${ }^{236} \mathrm{U}$-free CRM-112A standard solution and utilized to correct the contribution from the tail of ${ }^{238} \mathrm{U}$ on mass 236 , which was typically $\leq 0.1 \mathrm{ppm}$ of the ${ }^{238} \mathrm{U}$ signal.

\section{RESULTS AND DISCUSSION}

Characterization of dissolved, adsorbed, and solid species in the system enabled us to monitor the development of the $D$. vulgaris static biofilms under the six main conditions: biotic, abiotic, and mixed biotic and abiotic (henceforth, simply referred to as "mixed") with or without Fe and with excess electron donor. Furthermore, it revealed the extent of $U$ immobilization depending on the geochemical conditions and the available reducing agents. In addition, a combination of solid phase characterization and isotopic measurements allowed the identification of the uranium reduction mechanism(s) under complex conditions and provided insight into U(VI) reduction in the environment. Supplementary experiments including mixed and abiotic systems under electron donor limited conditions were examined in order to delineate the contribution of electron donor availability to $U$ immobilization and reduction. Unless otherwise specified, the results and discussion presented below focus on the six main biofilm systems with excess electron donor, as listed in Table S2.

3.1. Metabolism and Biofilm Establishment of $D$. vulgaris. The results presented in Figures 1 and S2 confirm the heterotrophic ability of Desulfovibrio vulgaris to couple the oxidation of an organic compound to the reduction of inorganic compounds, i.e., sulfate, ferric iron, or hexavalent uranium. The oxidation of lactate to acetate (consumption of dissolved lactate species and production of acetate as seen in Figures 1 and S1) is strictly correlated to the reduction of aqueous sulfate to sulfide in the system, in both the presence and absence of ferrihydrite. In all six cases, $\mathrm{SO}_{4}{ }^{2-}$ to $\mathrm{HS}^{-}$reduction plots mirror exactly the lactate to acetate oxidation curves. The concentration ratio of lactate to sulfate in the main systems was chosen to be equivalent to three times more electron donor than needed to reduce sulfate. Thus, only $1 / 3$ of the lactate present was necessary to reduce $10 \mathrm{mM}$ of sulfate, which is confirmed by data in Figures 1 and S2. The experiments were designed this way to guarantee excess electron donor and allow for biological reduction of hexavalent uranium.

Previous laboratory experiments ${ }^{33}$ demonstrated that, when exposed to $\mathrm{Fe}(\mathrm{III})$, sulfate, and $\mathrm{U}(\mathrm{VI})$ with lactate as an electron donor, $D$. vulgaris first reduces $\mathrm{Fe}(\mathrm{III})$, followed by $\mathrm{U}(\mathrm{VI})$ and finally sulfate. In order to ensure the presence of $\mathrm{HS}^{-}$, an agent capable of reducing uranium, it was crucial to take into consideration that property when designing our experiments. Biomass required $\sim 4$ days to fully develop. During this period, the electron acceptor in the form of sulfate was fully consumed and biofilms became electron acceptor limited (Figures 1 and S2). For the mixed and biotic systems, the biofilm was allowed to grow for 1 day to initiate establishment of the biofilm and accumulation of $\mathrm{Fe}$ (III) and sulfate reduction products. Uranium was then added to the reactor. This timeline was selected on the basis of our observation and previous studies reporting visible $D$. vulgaris biofilm formation $15 \mathrm{~h}$ after inoculation. ${ }^{34}$ This strategy enabled us to examine the behavior of uranium with coexisting microbial activity and a variety of reducing agents under varying carbonate concentrations $(5 \mathrm{mM}$ for the mixed system and $30 \mathrm{mM}$ for the biotic system). In the abiotic system, the biofilm was allowed to fully develop (4 days) and produce reduced iron and sulfur species before biomass inactivation and uranium addition. This approach allowed us to monitor the reduction of $U$ by abiotic reducing agents in the presence of inactivated biofilm that included EPS.

3.2. Uranium Immobilization and Reduction. Depending on the biofilm scenario, the extent of uranium immobilization varied between $85 \%$ and $100 \%$ (Figures 1 and S2) for the systems with excess electron donor. The highest immobilization was observed for biotic cases, where all of the dissolved $\mathrm{U}$ species present initially (in the form of $\mathrm{Ca} / \mathrm{Mg}-\mathrm{U}$ carbonate complexes, Table S3) were transformed and no adsorbed $\mathrm{U}(\mathrm{VI})$ was measured. In the mixed systems, the extent of immobilization was $98 \%$ for both $+\mathrm{Fe}$ and no-Fe cases and a small fraction of adsorbed U(VI) was identified within the immobilized part: $2 \%$ for no-Fe system and $8 \%$ for $+\mathrm{Fe}$ system. Significantly less uranium immobilization was measured for abiotic cases, where the no-Fe system yielded $85 \%$ immobilization (that included a $22 \%$ adsorbed U(VI) fraction) and the $+\mathrm{Fe}$ system immobilized $89 \%$ of the total $\mathrm{U}$ (including $19 \%$ adsorbed $U(V I))$. These results suggest that microbial $U$ reduction can be more effective and contribute to faster immobilization and reduction of uranium as compared to abiotic pathways.

Interestingly, the addition of $\mathrm{Fe}$ (III) minerals to the systems $(+\mathrm{Fe}$ cases $)$ had a minor impact on the overall immobilization and reduction of $\mathrm{U}$. However, the growth medium in all cases contained trace amounts of ferrous iron, and it was shown previously that the presence of a trace amount of ferrous iron in a $5 \mathrm{mM}$ bicarbonate solution enhances $U$ reduction by hydrogen sulfide. ${ }^{35}$ This suggests that hydrogen sulfide is an important and active $U$ reducing agent in mixed and abiotic systems (when amended with $5 \mathrm{mM}$ bicarbonate) and explains the similar level of $\mathrm{U}$ immobilization in the $+\mathrm{Fe}$ and no-Fe system (Figures 1 and S2).

In contrast to the cases discussed above, four additional biofilm systems run under electron donor limited conditions with $5 \mathrm{mM}$ bicarbonate were analyzed (Figure S3). The initial amendments included $60 \mathrm{mM}$ lactate and $30 \mathrm{mM}$ sulfate. Hence, complete sulfate reduction occurred and resulted in the depletion of the electron donor. No electron donor was available for biotic $\mathrm{U}(\mathrm{VI})$ reduction. In those systems, the extent of $U$ immobilization and reduction was significantly lower than in the electron acceptor limited systems and varied between $25 \%$ and $66 \%$ (Figure S3). This result is in agreement with field observations ${ }^{36}$ where organic carbon concentrations were shown to be a primary control on the extent of uranium removal from groundwater. Interestingly, the presence of $\mathrm{Fe}$ (III) minerals in the systems with electron donor limitation resulted in enhanced $U$ immobilization and reduction, yielding $66 \% \mathrm{U}$ immobilization (including $6 \%$ of adsorbed U(VI)) for the mixed $+\mathrm{Fe}$ system and $45 \% \mathrm{U}$ immobilization (including $6 \%$ of adsorbed $\mathrm{U}(\mathrm{VI})$ ) for the abiotic $+\mathrm{Fe}$ systems. In the absence of $\mathrm{Fe}(\mathrm{III})$ minerals, 55\% $\mathrm{U}$ immobilization (including $5 \%$ of adsorbed $\mathrm{U}(\mathrm{VI})$ ) was recorded for the mixed-no-Fe system and $25 \% \mathrm{U}$ immobilization (including $5 \%$ of adsorbed $\mathrm{U}(\mathrm{VI})$ ) for the abiotic-no-Fe systems. This finding suggests 
Table 1. Linear Combination Fits (LCF) for Uranium, Sulfur, and Iron Species in the Solid Phase Collected at the End of the Experiment for All Six Cases Considered ${ }^{a}$

\begin{tabular}{|c|c|c|c|c|c|c|c|c|}
\hline & \multicolumn{4}{|c|}{ noFe system } & & \multicolumn{3}{|c|}{ Fe system } \\
\hline \multirow{5}{*}{ Mix } & \multirow{2}{*}{ : } & n-crystalline & $\mathrm{UO}_{2}$ & $\begin{array}{c}\mathrm{U}(\mathrm{VI}) \\
\text { adsorbed }\end{array}$ & \multirow{2}{*}{ 点 } & \multirow{2}{*}{$\begin{array}{c}\text { non-crystalline } \\
\text { U(IV) } \\
89\end{array}$} & \multirow{2}{*}{$\begin{array}{c}\mathrm{UO}_{2} \\
0\end{array}$} & \multirow{2}{*}{$\begin{array}{c}\mathrm{U}(\mathrm{VI}) \text { adsorbed } \\
11\end{array}$} \\
\hline & & 91 & 0 & 9 & & & & \\
\hline & \multirow{3}{*}{$\frac{\grave{l}}{\frac{2}{5}}$} & FeS & $\mathrm{S}^{0}$ & $\mathrm{SO}_{4}^{2-}$ & \multirow{2}{*}{$\begin{array}{l}\frac{3}{\grave{L}} \\
\text { क }\end{array}$} & \multirow{2}{*}{$\begin{array}{c}\text { FeS } \\
80( \pm 1)^{*}\end{array}$} & \multirow{2}{*}{$\begin{array}{c}S^{0} \\
13( \pm 1)^{*}\end{array}$} & \multirow{2}{*}{$\begin{array}{c}\mathrm{SO}_{4}^{2-} \\
7( \pm 2)^{*}\end{array}$} \\
\hline & & $0( \pm 0.6)^{*}$ & $100( \pm 8)^{*}$ & $0( \pm 0.5)^{\star}$ & & & & \\
\hline & & & & & 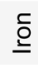 & $\begin{array}{c}\mathrm{FeS} \\
57( \pm 2)\end{array}$ & $\begin{array}{c}\mathrm{FeS}_{2} \\
10( \pm 3)\end{array}$ & $\begin{array}{c}\mathrm{Fe}^{3+} \\
32( \pm 4)\end{array}$ \\
\hline \multirow{5}{*}{ Biotic } & \multirow{2}{*}{ 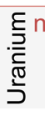 } & $\begin{array}{l}\text { on-crystalline } \\
\text { U(IV) }\end{array}$ & & $\begin{array}{c}\mathrm{U}(\mathrm{VI}) \\
\text { adsorbed }\end{array}$ & \multirow{2}{*}{ 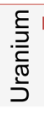 } & $\begin{array}{c}\text { non-crystalline } \\
\text { U(IV) }\end{array}$ & $\mathrm{UO}_{2}$ & $\mathrm{U}(\mathrm{VI})$ adsorbed \\
\hline & & $93( \pm 2)$ & $2( \pm 2)$ & $5( \pm 3)$ & & 94 & 0 & $6( \pm 3)$ \\
\hline & \multirow{3}{*}{ 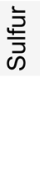 } & \multirow[t]{2}{*}{$\mathrm{FeS}$} & $\mathrm{S}^{0}$ & $\mathrm{SO}_{4}^{2-}$ & \multirow{2}{*}{ 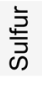 } & $\mathrm{FeS}$ & $\mathrm{S}^{0}$ & $\mathrm{SO}_{4}^{2-}$ \\
\hline & & & no data & & & 100 & 0 & 0 \\
\hline & & & & & 으 & $\begin{array}{c}\text { FeS } \\
82( \pm 8)\end{array}$ & $\begin{array}{c}\mathrm{FeS}_{2} \\
16( \pm 3)\end{array}$ & $\begin{array}{c}\mathrm{Fe}^{3+} \\
2( \pm 8)\end{array}$ \\
\hline \multirow{5}{*}{ Abiotic } & \multirow{2}{*}{ 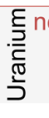 } & $\begin{array}{l}\text { on-crystalline } \\
\text { U(IV) }\end{array}$ & $\mathrm{UO}_{2}$ & $\begin{array}{c}\mathrm{U}(\mathrm{VI}) \\
\text { adsorbed }\end{array}$ & \multirow{2}{*}{ 竞 } & $\begin{array}{c}\text { non-crystalline } \\
\text { U(IV) }\end{array}$ & $\mathrm{UO}_{2}$ & $\mathrm{U}(\mathrm{VI})$ adsorbed \\
\hline & & $92( \pm 2)$ & $2( \pm 2)$ & $6( \pm 3)$ & & $94( \pm 3)$ & $3( \pm 2)$ & $3( \pm 3)$ \\
\hline & \multirow{3}{*}{ 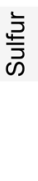 } & FeS & $\mathrm{S}^{0}$ & $\mathrm{SO}_{4}{ }^{2-}$ & \multirow{2}{*}{ 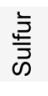 } & \multirow{2}{*}{$\begin{array}{c}\mathrm{FeS} \\
74( \pm 1)^{*}\end{array}$} & \multirow{2}{*}{$\begin{array}{c}S^{0} \\
25( \pm 1)^{*}\end{array}$} & $\mathrm{SO}_{4}{ }^{2-}$ \\
\hline & & $0^{*}$ & $100( \pm 3)^{*}$ & $0^{*}$ & & & & $1( \pm 2)^{\star}$ \\
\hline & & & & & 음 & $\begin{array}{c}\text { FeS } \\
66( \pm 7)\end{array}$ & $\begin{array}{c}\mathrm{FeS}_{2} \\
19( \pm 3)\end{array}$ & $\begin{array}{c}\mathrm{Fe}^{3+} \\
15( \pm 8)\end{array}$ \\
\hline
\end{tabular}

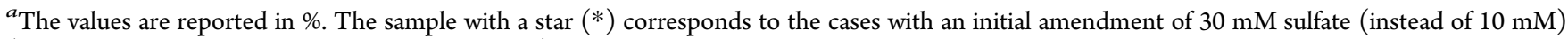
(more information in the Supporting Information).

that, under electron donor limited conditions, $\mathrm{Fe}$ (II) sulfide minerals (the product of $\mathrm{Fe}$ (III) and sulfate enzymatic reduction), aqueous sulfide, and $\mathrm{Fe}(\mathrm{II})$, as well as adsorbed $\mathrm{Fe}(\mathrm{II})$ on the $\mathrm{Fe}$ (III) minerals play an important role in the immobilization of $U$ by enhancing reductive transformation. However, when the electron donor becomes available, biotic reduction becomes more significant.

Furthermore, because all the available lactate is oxidized under electron donor limited conditions, there is accumulation of aqueous carbonate species (acetate and $\mathrm{CO}_{2}$ are the products of lactate oxidation in this system). A buildup of carbonate species in solution likely triggered the observed release of adsorbed $\mathrm{U}(\mathrm{VI})$ after the initial $\mathrm{U}(\mathrm{VI})$ reduction/ sorption phase ${ }^{36}$ (Figure S3). At the same time, however, under electron donor limited conditions, and with the accumulation of bicarbonate in solution, aqueous U(VI) reduction is limited by minimal microbial activity (due to the lack of electron donor), by the lack of abiotic $\mathrm{U}$ reduction mediated by redoxactive minerals, and by the inability of aqueous sulfide to reduce carbonate-complexed U(VI).

Analysis of the solid phase (of the main six systems with electron donor excess) by X-ray absorption spectroscopy revealed uranium speciation in the immobilized fraction. Thorough examination of extended X-ray absorption fine structure (EXAFS) spectra (Figure S4) for the uranium compounds and subsequent comparison to reference compounds (LCF, Table 1) showed that, regardless of the $U$ reduction scenario (biotic, abiotic, mixed), reduced uranium was present almost entirely as noncrystalline U(IV) species (89-94\%). The presence of the microbial biofilm favored the formation of noncrystalline U(IV) by binding U(IV) within the biofilm matrix, and by this, precluding the precipitation of uraninite. This finding confirms the results presented previously $^{15}$ that correlated the formation of noncrystalline $\mathrm{U}(\mathrm{IV})$ with the presence of bacterial EPS. Moreover, noncrystalline $U($ IV) species were shown to be associated with cell-bound phosphate groups pointing to the involvement of bacterial phospholipids (one of the components of EPS). ${ }^{37-39}$ Our results confirm as well the hypothesis presented in the field study, ${ }^{26}$ proposing a role for the biofilm matrix in capturing U(IV).

However, our results are in contrast to a recent study ${ }^{40}$ where enzymatic $U$ reduction in the presence of a $D$. vulgaris biofilm resulted in the formation of nanoparticulate crystalline uraninite. This inconsistency can be explained by the difference in initial reduction conditions: in the current study, biofilm development was first allowed to grow for 1 day, followed by the introduction of $\mathrm{U}(\mathrm{VI})$, mimicking the arrival of a $\mathrm{U}(\mathrm{VI})$ plume into an aquifer with a well-established microbial community. In the above-mentioned study, ${ }^{40} \mathrm{U}(\mathrm{VI})$ was introduced at the same time as the D. vulgaris inoculum, allowing for concurrent bacterial growth and $U$ reduction, followed by sulfate reduction. ${ }^{33}$ Under these conditions, precipitation of crystalline uraninite is favored as $\mathrm{U}(\mathrm{VI})$ reduction occurs prior to the development of a biofilm matrix that can interact with $\mathrm{U}(\mathrm{IV})$ ions.

3.3. Uranium Reduction Mechanism. We accounted for the major $\mathrm{U}(\mathrm{VI})$ reduction pathways in the environment: (i) enzymatic reduction, for which $\mathrm{U}(\mathrm{VI})$ species must be aqueous in order for bacteria to catalyze the reduction; (ii) abiotic 
Table 2. $\delta^{238} U$ Values along with Corresponding Fraction of Uranium Remaining in Solution $\left(C / C_{0}\right)$ for Mixed, Biotic, and Abiotic Systems in the Absence (no-Fe) or Presence of Iron $(+\mathrm{Fe})^{a}$

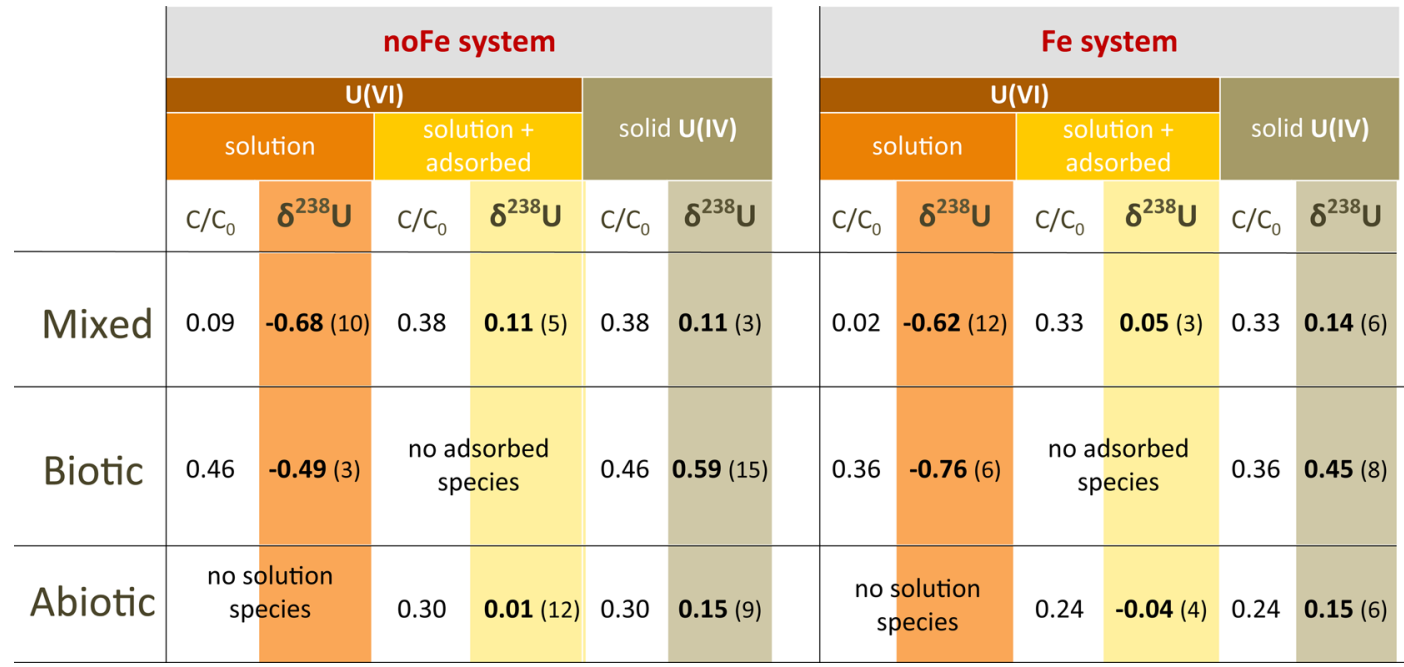

${ }^{a}$ Numbers in the brackets represent the 2 S.D. $\left(10^{-2}\right)$ for each of the isotopic values.

reduction mediated by redox active minerals, in which case $\mathrm{U}(\mathrm{VI})$ must be adsorbed onto the mineral phase to enable the reduction; and (iii) abiotic reduction by dissolved sulfide at circumneutral $\mathrm{pH}$. Reduction by aqueous sulfide is partially inhibited at bicarbonate concentrations $>5 \mathrm{mM}$ while full inhibition was reported at concentrations $>15 \mathrm{mM}^{41}$ In order to uncover the mechanism of $U$ reduction in the mixed system (by comparing the results to biotic and abiotic systems), (1) we focused on the characterization of $S$ and $\mathrm{Fe}$ in the solid phase and their transformation as an indicator of $\mathrm{FeS}$ and $\mathrm{HS}^{-}$ involvement in $U$ reduction, and (2) we collected and compared the isotopic signatures of $U$ in the aqueous and solid phases.

3.3.1. S and Fe Solid Phase Characterization. X-ray absorption near edge structure (XANES) spectra (Figure S5) and subsequent comparison to reference compounds (LCF, Table 1) revealed the sulfur and iron speciation in the solid phase of each biofilm scenario. For the mixed-no-Fe and abiotic-no-Fe systems, elemental sulfur $\left(S^{0}\right)$ was detected exclusively, whereas for mixed $+\mathrm{Fe}$ and abiotic $+\mathrm{Fe}$ systems, a fraction of the ferrous iron sulfide mineral mackinawite $(\mathrm{FeS})$ and a small fraction of sulfate were reported in addition to $S^{0}$. For the biotic $+\mathrm{Fe}$ system, sulfur was present in the form of reduced sulfide $(\mathrm{FeS})$ but no $S^{0}$ was detected. Experimental limitations resulted in no detectable $S$ species for the biotic-no$\mathrm{Fe}$ case. XANES spectra of iron species indicated that the majority of the iron present at the end of the experiments was reduced (68-98\%). The LCF reported a mixture of $\mathrm{FeS}$ (mackinawite) and an undefined iron sulfide phase as a product of $\mathrm{Fe}(\mathrm{III})$ and sulfate reduction by $D$. vulgaris. Mackinawite was demonstrated to be the first mineral to precipitate in the subsurface under sulfate-reducing conditions, ${ }^{42}$ and its aging leads to the formation of more stable ferrous sulfide minerals such as greigite or pyrite.

Formation of elemental sulfur coupled to the reduction of $\mathrm{U}(\mathrm{VI})$ by dissolved sulfide or $\mathrm{Fe}(\mathrm{II})$ sulfide minerals is a welldocumented process. ${ }^{35,41,43}$ The presence of elemental sulfur in the abiotic and mixed conditions is direct evidence for the involvement of a sulfide-based reductant in the reduction of $\mathrm{U}(\mathrm{VI})$ coupled to the oxidation of $\mathrm{S}^{2-}$ to $\mathrm{S}^{0}$. Dissolved species measurements support this conclusion: sulfate was completely removed and sulfide species accumulated (Figures 1 and S1). However, the concentration of dissolved sulfide is lower than the expected $10 \mathrm{mM}$ in all cases (detectable sulfide concentration ranges from 7.5 to $8 \mathrm{mM}$ at the end of the experiment), suggesting sequestration of $20-25 \%$ of the $\mathrm{S}^{2-}$ produced with $\mathrm{Fe}(\mathrm{II})$ and/or direct oxidation of $\mathrm{S}^{2-}$ to $\mathrm{S}^{0}$ coupled to $\mathrm{U}(\mathrm{VI})$ reduction to $\mathrm{U}(\mathrm{IV})$.

3.3.2. Isotopic Measurements. A recent study ${ }^{28}$ demonstrated that the isotopic signature of enzymatically reduced uranium (i.e., the enrichment of ${ }^{238} \mathrm{U}$ in the reduced $\mathrm{U}$ pool) was easily distinguishable from the isotopic signature of uranium reduced abiotically by sulfide-bearing reductants (i.e., no isotope fractionation). Thus, $U$ isotopes can be used as a tool to determine the exact mechanism of $U$ reduction in the studied systems. The isotopic signature was measured for unreacted $\mathrm{U}(\mathrm{VI})$ and the corresponding $\mathrm{U}(\mathrm{IV})$ solid fraction for all the tested cases. For the biotic systems, U(VI) measurements correspond to the remaining aqueous $\mathrm{U}(\mathrm{VI})$. For the mixed and abiotic cases (containing $5 \mathrm{mM}$ of bicarbonate), $\mathrm{U}(\mathrm{VI})$ could be present both as dissolved and adsorbed species and the isotopic signature was reported either for aqueous or for a combination of aqueous and adsorbed (i.e., after extraction of the adsorbed species).

Table 2 presents the $\delta^{238} \mathrm{U}$ values together with the corresponding fraction of aqueous uranium removed $\left(C / C_{0}\right)$ for all six scenarios. In the case of the biotic systems, recorded $\delta^{238} \mathrm{U}$ values of the remaining $\mathrm{U}(\mathrm{VI})$ in solution range from $-0.49( \pm 0.03) \%$ for the biotic-no-Fe system to -0.76 $( \pm 0.06) \%$ o for the biotic $+\mathrm{Fe}$ system. These results imply the enrichment of the light isotope in the unreacted U(VI) fraction. Correspondingly, the biologically produced U(IV) solid exhibits a strong positive signature $\left(\delta^{238} \mathrm{U}=0.59\right.$ $( \pm 0.15) \%$ o for the biotic-no-Fe system and $0.45( \pm 0.08) \%$ for the biotic $+\mathrm{Fe}$ system), indicating the preferential reduction of heavy $U$ isotopes and their accumulation in the reduced phase. ${ }^{27,28,32,44-46}$ These results are consistent with biologically mediated reduction.

For the abiotic cases, the results show that there was no sustained fractionation in $\mathrm{U}(\mathrm{VI})$ (solution plus adsorbed species) when $U$ is reduced by redox-active minerals or dissolved sulfide: the $\delta^{238} \mathrm{U}$ value reaches $0.01( \pm 0.12) \%$ for 
the abiotic-no-Fe system and $-0.04( \pm 0.04) \%$ o for the abiotic $+\mathrm{Fe}$ system. At the same time, U(IV) solid $\delta^{238} \mathrm{U}$ values yield $0.15 \%$ o $( \pm 0.09) \%$ or $0.15 \%$ o $( \pm 0.06) \%$, suggesting little $U$ isotope fractionation.

For the mixed system, where a combination of biotic and abiotic $U$ reducing pathways was possible, a significant difference in $U$ isotope fractionation in the solution-only $\mathrm{U}(\mathrm{VI})$ samples and the solution + adsorbed $\mathrm{U}(\mathrm{VI})$ samples was detected. While measurements of isotopic signature for the remaining solution $\mathrm{U}(\mathrm{VI})$ indicate enrichment of the light isotope in the dissolved fraction $\left(\delta^{238} \mathrm{U}=-0.68( \pm 0.10) \%\right.$ o for no-Fe system and $\delta^{238} \mathrm{U}=-0.62( \pm 0.12) \%$ o for Fe system $)$, after desorption of unreacted U(VI) from the solid phase, $\delta^{238} \mathrm{U}$ values converge toward zero $(0.11( \pm 0.05) \%$ o for the no-Fe system and $0.05( \pm 0.05) \%$ o for the Fe system $)$. This variation stems from the distribution of $\mathrm{U}(\mathrm{VI})$ species in the system, with a majority of $\mathrm{U}(\mathrm{VI})$ being adsorbed. A minor dissolved fraction (representing less than $9 \%$ of total $U$ ) was accessible for direct enzymatic reduction, thus adopting a slightly enzymatic isotopic signature (unreacted solution U(VI) enriched in the light isotope $\left.{ }^{235} \mathrm{U}\right)$. However, after the desorption of adsorbed $\mathrm{U}(\mathrm{VI})$ at the same experimental time points, the enzymatic signature is overprinted by that of the desorbed species, resulting in near zero $\delta^{238} \mathrm{U}$ values. At the same time, $\mathrm{U}(\mathrm{IV})$ solids display $\delta^{238} \mathrm{U}$ values of $0.11( \pm 0.03) \%$ o for the no-Fe system and $0.14( \pm 0.06) \%$ o for the Fe system, showing little isotope fractionation and thus confirming that the majority of the initially present $\mathrm{U}(\mathrm{VI})$ in the mixed systems was adsorbed rapidly and reduced abiotically.

3.3.3. Mechanism of U(VI) Reduction in the Biofilms. The main objective of our study was to delineate the mechanism of $\mathrm{U}(\mathrm{VI})$ reduction in systems in which a mixture of biotic and abiotic reducing agents are available. To do so, we contrasted our laboratory mixed system with biotic and abiotic ones. Surprisingly, the mixed system, despite the presence of active biomass, predominantly displayed characteristics of the abiotic system rather than mixed characteristics of the biotic and abiotic cases. This finding implies that biotic U(VI) reduction in mixed systems is restricted due to limited availability of aqueous $\mathrm{U}(\mathrm{VI})$ species which, in turn, is controlled by various factors, including the concentration of aqueous carbonate and availability of sorption-active surfaces. During our experiments, the lower carbonate concentration $(5 \mathrm{mM})$ allowed dissolved and adsorbed $\mathrm{U}(\mathrm{VI})$ to co-occur, whereas the higher carbonate concentration $(30 \mathrm{mM})$ allowed dissolved U-carbonate complexes to be present exclusively. At the higher carbonate concentration, the biotic isotope signature and the absence of detectable elemental sulfur suggest an exclusively enzymatic $U$ reduction, which outcompetes abiotic reducing agents, such as hydrogen sulfide or Fe(II) sulfide minerals. On the other hand, when the carbonate concentration was $5 \mathrm{mM}$, the majority of hexavalent $U$ was adsorbed on available surfaces, resulting in $U$ reduction preferentially mediated via abiotic pathways while enzymatic $U$ reduction was limited to the marginal aqueous $\mathrm{U}(\mathrm{VI})$ fraction available for direct microbial interaction. Preferential abiotic reduction was evidenced by the lack of significant fractionation in the isotopic signature and the presence of elemental sulfur. Similar findings showing that $\mathrm{U}(\mathrm{VI})$ speciation controls the mechanism of uranium reduction (whether biotic or abiotic) were reported for the iron-reducing bacterium Shewanella putrefaciens in the presence of iron minerals $^{47}$ and for the SRB Desulfovibrio aerotolerans. ${ }^{35}$ This combination of results strongly suggests that $\mathrm{U}(\mathrm{VI})$ speciation may be one of the critical factors controlling whether $\mathrm{U}(\mathrm{VI})$ is reduced via a biotic or abiotic mechanism, regardless of the microbial community.

3.4. Environmental Implications. As part of this study, we identified the mechanism(s) of $\mathrm{U}(\mathrm{VI})$ reduction under a variety of geochemical conditions and showed that the presence of biofilms (whether active or inactive) resulted in the accumulation of noncrystalline $\mathrm{U}(\mathrm{IV})$ species rather than uraninite.

In the systems with the lower carbonate concentration and the availability of both biotic and abiotic reducing agents, enzymatic $U$ reduction was outcompeted by abiotic processes due to the partitioning of $U(V I)$ onto the mineral phase or its interaction with dissolved biologically produced sulfide. These results suggest that the model proposed previously ${ }^{26}$ is accurate, implying that $U$ reduction in the environment is mediated by mackinawite and followed by the sequestration of $\mathrm{U}(\mathrm{IV})$ in the biofilm matrix. In addition to the carbonate concentration, the mineral surface could play an important role in controlling the dissolved/sorbed U(VI) ratio. During our experiments, iron sulfides were freshly formed, with the majority of their sorption sites available for U(VI) complexation. However, under environmental conditions, the situation is far more complex and several factors can determine the equilibrium between the sorbed and aqueous fraction of U(VI). For example, competitive adsorption of natural organic matter onto the $\mathrm{Fe}$ (II) sulfide minerals should be taken into consideration. ${ }^{48}$ If environmental conditions preclude the quantitative sorption of $\mathrm{U}(\mathrm{VI})$, biotic processes may become significant and even outcompete abiotic $U$ reduction at relatively low carbonate concentrations.

Several studies demonstrated that the addition of $30-37 \mathrm{mM}$ bicarbonate to the U-contaminated subsurface with a background concentration of bicarbonate of $\sim 6 \mathrm{mM}^{49}$ allows for enzymatic $U$ reduction and enhanced $U$ immobilization. ${ }^{50,51}$ This is supported by our results (biotic system) and indicates the effectiveness of biological $U$ reduction in the subsurface in comparison to abiotic pathways if $\mathrm{U}(\mathrm{VI})$ is in the aqueous phase. Moreover, microbial metabolic activity can contribute to an increase in the bicarbonate concentration as a result of $\mathrm{CO}_{2}$ production. This, in turn, was proposed to promote the desorption of $\mathrm{U}(\mathrm{VI})$ from the solid phase and favor microbial reduction. ${ }^{36,51}$ However, on the basis of our experiments, the oxidation of $20 \mathrm{mM}$ lactate could not account for a large enough increase in the carbonate concentration to enhance the involvement of enzymatic $\mathrm{U}(\mathrm{VI})$ reduction in the overall reductive immobilization of $U$. Only higher concentrations of lactate $(60 \mathrm{mM})$, as shown in this study, resulted in the enhanced release of sorbed U(VI) (Figure S3), suggesting that the concentration of added electron donor and the extent of its oxidation during bioremediation are also important factors controlling whether biotic or abiotic mechanisms of $\mathrm{U}(\mathrm{VI})$ reduction dominate.

Laboratory-based approaches adopted in this study allowed us to fill in knowledge gaps and bridge findings derived from field observations at a U-contaminated site (Rifle, Colorado). Isotopic measurement of the groundwater at this field site ${ }^{27}$ revealed that unreacted aqueous $\mathrm{U}(\mathrm{VI})$ is enriched in the light isotope, in agreement with a biotic isotope signature. ${ }^{28}$ Thus, the combination of these two results suggest a primarily biotic mechanism for $\mathrm{U}(\mathrm{VI})$ reduction during remediation. In contrast, as discussed above, another study ${ }^{26}$ concluded that abiotic reductive mechanisms were dominant in the subsurface. 
These two results would seem to be in contradiction. However, the findings in this study allow us to conclude that both studies actually show the same results when interpreted correctly. The field isotope study ${ }^{27}$ probed only solution U(VI) and found a light isotope signature later shown to be biotic. This only shows that reduction of aqueous $\mathrm{U}(\mathrm{VI})$ is biological. However, sorbed $\mathrm{U}(\mathrm{VI})$ is most likely reduced via abiotic processes, which is consistent with the study of Bargar et al. ${ }^{26}$ Thus, for a full interpretation of isotope data, it is critical to obtain aqueous and solid-phase isotopic samples.

Two major field implications of this study are evident. First, biofilm growth in the subsurface will result in the formation of noncrystalline $\mathrm{U}(\mathrm{IV})$ regardless of the mechanism of reduction. As discussed above, noncrystalline U(IV) species are relatively more reactive and susceptible to reoxidation than uraninite, thus raising concerns about the long-term effectiveness of this approach to contaminant immobilization. For this reason, research focused on stability and aging of in situ U(IV) (potential increase in crystallinity and resistance to remobilization) should be prioritized in order to fully understand the feasibility of U bioremediation. Second, this study supports and confirms the previous laboratory and field work demonstrating that $\mathrm{U}(\mathrm{VI})$ speciation, in particular its partitioning and complexation behavior, controls whether a biotic or abiotic mechanism of reduction prevails. A recent study ${ }^{51}$ showed no significant differences in the microbial communities for the same field site with either elevated or background bicarbonate concentrations, confirming the hypothesis that the mechanism of $U$ reduction and the reduction rates are controlled by geochemical factors, such as $\mathrm{U}(\mathrm{VI})$ speciation, rather than biological diversity. In fact, geochemical conditions were previously found to also indirectly control biofilm formation. ${ }^{15}$ These findings underscore the complex interaction between geochemical and biological processes occurring at $U$ contaminated sites and the need to deconvolute individual contributions to optimize remediation strategies.

Besides the processes occurring in the terrestrial subsurface, the findings presented here provide also important implications for marine environments, particularly for anoxic marine basins, such as the Black Sea. Despite the high sulfide levels in the water column, the stability of U(VI) carbonate complexes in seawater appears to prohibit direct abiotic $U$ reduction in the water column. Rather, $\mathrm{U}(\mathrm{VI})$ is assumed to be removed from the water column by pore water diffusion into the sediment and subsequent reduction and precipitation. ${ }^{52,53}$ These authors speculated that $\mathrm{U}(\mathrm{VI})$ reduction in the sediment occurs abiotically with $\mathrm{H}_{2} \mathrm{~S}$, although it was not clear why this reaction would proceed in the sediments but not in the open water column at similar sulfide levels. The results of this study show that, in the presence of biofilms and high carbonate levels (allowing the formation of stable dissolved $\mathrm{U}(\mathrm{VI})$ carbonate complexes), microorganisms are able to effectively reduce $\mathrm{U}(\mathrm{VI})$. This conclusion is in agreement with the heavy $\mathrm{U}$ isotope signatures observed in anoxic marine sediments ${ }^{54,55}$ and the recent finding that such signatures are a clear indicator of biotic $\mathrm{U}$ reduction. ${ }^{28}$

\section{ASSOCIATED CONTENT}

\section{S Supporting Information}

The Supporting Information is available free of charge on the ACS Publications website at DOI: 10.1021/acs.est.5b01769.
Additional materials and methods, figures, and tables (PDF)

\section{AUTHOR INFORMATION}

\section{Corresponding Author}

*Phone: +41 2169350 01; email: rizlan.bernier-latmani@epfl. ch.

\section{Notes}

The authors declare no competing financial interest.

\section{ACKNOWLEDGMENTS}

The work at EPFL was supported by the Swiss National Science Foundation (Grant \# 200020-144335). XAS was carried out at SSRL, operated by Stanford University on behalf of the U.S. DOE (BES) and supported by SSRL ERSP and BER-ERSD. We thank the SSRL Radiation Protection Group and Luca Loreggian for their help during operation and data collection at SSRL.

\section{REFERENCES}

(1) Francis, A. J.; Dodge, C. J.; Lu, F.; Halada, G. P.; Clayton, C. R. XPS and XANES Studies of Uranium Reduction by Clostridium sp. Environ. Sci. Technol. 1994, 28, 636-639.

(2) Lovley, D. R.; Roden, E. E.; Phillips, E. J. P.; Woodward, J. C. Enzymatic iron and uranium reduction by sulfate-reducing bacteria. Mar. Geol. 1993, 113, 41-53.

(3) Lovley, D. R.; Phillips, E. J.; Gorby, Y. A.; Landa, E. R. Microbial reduction of uranium. Nature 1991, 350, 413-416.

(4) Lovley, D. R.; Phillips, E. J. Reduction of uranium by Desulfovibrio desulfuricans. Appl. Environ. Microbiol. 1992, 58, 850856.

(5) Sani, R.; Peyton, B.; Smith, W.; Apel, W.; Petersen, J. Dissimilatory reduction of $\mathrm{Cr}(\mathrm{VI}), \mathrm{Fe}(\mathrm{III})$, and $\mathrm{U}(\mathrm{VI})$ by Cellulomonas isolates. Appl. Microbiol. Biotechnol. 2002, 60, 192-199.

(6) Maleke, M.; et al. Optimization of a bioremediation system of soluble uranium based on the biostimulation of an indigenous bacterial community. Environ. Sci. Pollut. Res. 2015, 22, 8442-8450.

(7) Newsome, L.; Morris, K.; Lloyd, J. R. The biogeochemistry and bioremediation of uranium and other priority radionuclides. Chem. Geol. 2014, 363, 164-184.

(8) Leigh, M. B.; et al. Microbial communities biostimulated by ethanol during uranium (VI) bioremediation in contaminated sediment as shown by stable isotope probing. Front. Environ. Sci. Eng. 2015, 9, 453-464.

(9) Kalin, M.; Wheeler, W. N.; Meinrath, G. The removal of uranium from mining waste water using algal/microbial biomass. J. Environ. Radioact. 2004, 78, 151-177.

(10) Renshaw, J. C.; Lloyd, J. R.; Livens, F. R. Microbial interactions with actinides and long-lived fission products. C. R. Chim. 2007, 10, 1067-1077.

(11) Merroun, M.; Nedelkova, M.; Rossberg, A.; Hennig, C.; Selenska-Pobell, S. Interaction mechanisms of bacterial strains isolated from extreme habitats with uranium. Radiochim. Acta 2009, 94, 723729.

(12) Suzuki, Y.; Banfield, J. F. Geomicrobiology of uranium. Rev. Mineral. Geochem. 1999, 38, 393-432.

(13) Junier, P.; et al. Metal reduction by spores of Desulfotomaculum reducens. Environ. Microbiol. 2009, 11, 3007-3017.

(14) Lovley, D. R.; Phillips, E. J. P. Bioremediation of uranium contamination with enzymatic uranium reduction. Environ. Sci. Technol. 1992, 26, 2228-2234.

(15) Stylo, M.; et al. Biogeochemical Controls on the Product of Microbial U(VI) Reduction. Environ. Sci. Technol. 2013, 47, 1235112358.

(16) Decho, A. W. Microbial biofilms in intertidal systems: an overview. Cont. Shelf Res. 2000, 20, 1257-1273. 
(17) Kolter, R. Surfacing views of biofilm biology. Trends Microbiol. 2005, 13, 1-2.

(18) Nelson, Y.; Lion, L.; Shuler, M.; Ghiorse, W. Lead Binding to Metal Oxide and Organic Phases of Natural Aquatic Biofilms. Limnol. Oceanogr. 1999, 44, 1715-1729.

(19) Guibaud, G.; Comte, S.; Bordas, F.; Dupuy, S.; Baudu, M. Comparison of the complexation potential of extracellular polymeric substances (EPS), extracted from activated sludges and produced by pure bacteria strains, for cadmium, lead and nickel. Chemosphere 2005, 59, 629-638.

(20) Sutherland, I. W. Biofilm exopolysaccharides: a strong and sticky framework. Microbiology 2001, 147, 3-9.

(21) Baker, M. G.; Lalonde, S. V.; Konhauser, K. O.; Foght, J. M. Role of Extracellular Polymeric Substances in the Surface Chemical Reactivity of Hymenobacter aerophilus, a Psychrotolerant Bacterium. Appl. Environ. Microbiol. 2010, 76, 102-109.

(22) Konhauser, K. O.; Fisher, Q. J.; Fyfe, W. S.; Longstaffe, F. J.; Powell, M. A. Authigenic mineralization and detrital clay binding by freshwater biofilms: The Brahmani river, India. Geomicrobiol. J. 1998, $15,209-222$.

(23) Marshall, M. J.; et al. c-Type Cytochrome-Dependent Formation of U(IV) Nanoparticles by Shewanella oneidensis. PLoS Biol. 2006, 4, e268.

(24) Cerrato, J. M.; et al. Relative Reactivity of Biogenic and Chemogenic Uraninite and Biogenic Noncrystalline U(IV). Environ. Sci. Technol. 2013, 47, 9756-9763.

(25) Alessi, D. S.; et al. Speciation and Reactivity of Uranium Products Formed during in Situ Bioremediation in a Shallow Alluvial Aquifer. Environ. Sci. Technol. 2014, 48, 12842-12850.

(26) Bargar, J. R.; et al. Uranium redox transition pathways in acetateamended sediments. Proc. Natl. Acad. Sci. U. S. A. 2013, 110, 45064511.

(27) Bopp, C. J.; et al. Uranium 238U/235U Isotope Ratios as Indicators of Reduction: Results from an in situ Biostimulation Experiment at Rifle, Colorado, U.S.A. Environ. Sci. Technol. 2010, 44, 5927-5933.

(28) Stylo, M.; et al. Uranium Isotopes Fingerprint Biotic Reduction. Proc. Natl. Acad. Sci. U. S. A. 2015, 112, 5619-5624.

(29) Zane, G. M.; Yen, H. B.; Wall, J. D. Effect of the Deletion of qmoABC and the Promoter-Distal Gene Encoding a Hypothetical Protein on Sulfate Reduction in Desulfovibrio vulgaris Hildenborough. Appl. Environ. Microbiol. 2010, 76, 5500-5509.

(30) Cline, J. D. Spectrophotometric determination of hydrogen sulfide in natural waters. Limnol. Oceanogr. 1969, 14, 454-458.

(31) Richter, S.; et al. New average values for the $\mathrm{n}(238 \mathrm{U}) / \mathrm{n}(235 \mathrm{U})$ isotope ratios of natural uranium standards. Int. J. Mass Spectrom. 2010, 295, 94-97.

(32) Weyer, S.; et al. Natural fractionation of $238 \mathrm{U} / 235 \mathrm{U}$. Geochim. Cosmochim. Acta 2008, 72, 345-359.

(33) Elias, D. A.; Suflita, J. M.; McInerney, M. J.; Krumholz, L. R. Periplasmic Cytochrome c3 of Desulfovibrio vulgaris Is Directly Involved in H2-Mediated Metal but Not Sulfate Reduction. Appl. Environ. Microbiol. 2004, 70, 413-420.

(34) Clark, M. E.; Edelmann, R. E.; Duley, M. L.; Wall, J. D.; Fields, M. W. Biofilm formation in Desulfovibrio vulgaris Hildenborough is dependent upon protein filaments. Environ. Microbiol. 2007, 9, 28442854.

(35) Boonchayaanant, B.; Gu, B.; Wang, W.; Ortiz, M. E.; Criddle, C. $\mathrm{S}$. Can microbially-generated hydrogen sulfide account for the rates of $\mathrm{U}(\mathrm{VI})$ reduction by a sulfate-reducing bacterium? Biodegradation 2010, 21, 81-95.

(36) Williams, K. H.; et al. Acetate Availability and its Influence on Sustainable Bioremediation of Uranium-Contaminated Groundwater. Geomicrobiol. J. 2011, 28, 519-539.

(37) Alessi, D. S.; et al. The product of microbial uranium reduction includes multiple species with U(IV)-phosphate coordination. Geochim. Cosmochim. Acta 2014, 131, 115-127.

(38) Bernier-Latmani, R.; et al. Non-uraninite Products of Microbial U(VI) Reduction. Environ. Sci. Technol. 2010, 44, 9456-9462.
(39) Fletcher, K. E.; et al. U(VI) Reduction to Mononuclear U(IV) by Desulfitobacterium Species. Environ. Sci. Technol. 2010, 44, 47054709.

(40) Zhou, C.; Vannela, R.; Hyun, S. P.; Hayes, K. F.; Rittmann, B. E. Growth of Desulfovibrio vulgaris When Respiring U(VI) and Characterization of Biogenic Uraninite. Environ. Sci. Technol. 2014, $48,6928-6937$.

(41) Hua, B.; Xu, H.; Terry, J.; Deng, B. Kinetics of Uranium(VI) Reduction by Hydrogen Sulfide in Anoxic Aqueous Systems. Environ. Sci. Technol. 2006, 40, 4666-4671.

(42) Benning, L. G.; Wilkin, R. T.; Barnes, H. L. Reaction pathways in the Fe-S system below $100^{\circ} \mathrm{C}$. Chem. Geol. 2000, 167, 25-51.

(43) Hyun, S. P.; Davis, J. A.; Sun, K.; Hayes, K. F. Uranium(VI) Reduction by Iron(II) Monosulfide Mackinawite. Environ. Sci. Technol. 2012, 46, 3369-3376.

(44) Abe, M.; Suzuki, T.; Fujii, Y.; Hada, M.; Hirao, K. An ab initio molecular orbital study of the nuclear volume effects in uranium isotope fractionations. J. Chem. Phys. 2010, 129, 164309.

(45) Basu, A.; Sanford, R. A.; Johnson, T. M.; Lundstrom, C. C.; Löffler, F. E. Uranium isotopic fractionation factors during U(VI) reduction by bacterial isolates. Geochim. Cosmochim. Acta 2014, 136, $100-113$.

(46) Wang, X.; Johnson, T. M.; Lundstrom, C. C. Isotope fractionation during oxidation of tetravalent uranium by dissolved oxygen. Geochim. Cosmochim. Acta 2015, 150, 160-170.

(47) Behrends, T.; Van Cappellen, P. Competition between enzymatic and abiotic reduction of uranium(VI) under iron reducing conditions. Chem. Geol. 2005, 220, 315-327.

(48) Gu, B.; Mehlhorn, T. L.; Liang, L.; McCarthy, J. F. Competitive adsorption, displacement, and transport of organic matter on iron oxide: I. Competitive adsorption. Geochim. Cosmochim. Acta 1996, 60, 1943-1950.

(49) Long, P. E.; et al. Bicarbonate impact on U(VI) bioreduction in a shallow alluvial aquifer. Geochim. Cosmochim. Acta 2015, 150, 106124.

(50) Fox, P. M.; et al. Rate-limited U(VI) desorption during a smallscale tracer test in a heterogeneous uranium-contaminated aquifer. Water Resour. Res. 2012, 48, W05512.

(51) Long, P. E.; et al. Bicarbonate impact on U(VI) bioreduction in a shallow alluvial aquifer. Geochim. Cosmochim. Acta 2015, 150, 106124.

(52) Anderson, R. F.; Fleisher, M. Q.; LeHuray, A. P. Concentration, oxidation state, and particulate flux of uranium in the Black Sea. Geochim. Cosmochim. Acta 1989, 53, 2215-2224.

(53) Klinkhammer, G. P.; Palmer, M. R. Uranium in the oceans: Where it goes and why. Geochim. Cosmochim. Acta 1991, 55, 17991806.

(54) Andersen, M. B.; et al. A modern framework for the interpretation of $238 \mathrm{U} / 235 \mathrm{U}$ in studies of ancient ocean redox. Earth Planet. Sci. Lett. 2014, 400, 184-194.

(55) Noordmann, J.; et al. Uranium and molybdenum isotope systematics in modern euxinic basins: Case studies from the central Baltic Sea and the Kyllaren fjord (Norway). Chem. Geol. 2015, 396, $182-195$. 